\title{
Time evolution of high-altitude plasma bubbles imaged at geomagnetic conjugate points
}

\author{
K. Shiokawa ${ }^{1}$, Y. Otsuka ${ }^{1}$, T. Ogawa ${ }^{1}$, and P. Wilkinson ${ }^{2}$ \\ ${ }^{1}$ Solar-Terrestrial Environment Laboratory, Nagoya University, Toyokawa 442-8507, Japan \\ ${ }^{2}$ IPS Radio and Space Services, Haymarket, New South Wales 1240, Australia
}

Received: 14 January 2004 - Revised: 9 June 2004 - Accepted: 17 June 2004 - Published: 23 September 2004

Part of Special Issue "Equatorial and low latitude aeronomy"

\begin{abstract}
Temporal and spatial evolution of two highaltitude plasma bubbles (evening and midnight) was observed on 4 April 2002, at geomagnetic conjugate points at Sata, Japan (magnetic latitude $24^{\circ} \mathrm{N}$ ), and Darwin, Australia (magnetic latitude $22^{\circ} \mathrm{S}$ ), using two 630-nm airglow imagers. The apex height of the bubbles reached $\sim 1500 \mathrm{~km}$. The upward velocity of the evolution was faster in the evening $(\sim 170 \mathrm{~m} / \mathrm{s}$ at $20: 00-21: 00 \mathrm{LT})$ than around midnight ( $\sim 28 \mathrm{~m} / \mathrm{s}$ at 23:00-00:00 LT). Bifurcating features of the bubbles into a smaller scale size of $\sim 50 \mathrm{~km}$ were clearly seen for both the evening and midnight bubbles, showing fairly good conjugacy between the Northern and Southern Hemispheres.
\end{abstract}

Key words. Ionosphere (Equatorial ionosphere; Ionospheric irregularities); Atmospheric composition and structure (airglow and aurora).

\section{Introduction}

Equatorial plasma bubble is commonly seen in the postsunset equatorial latitudes as a result of the Rayleigh-Taylor instability, where the low-density plasma on the bottomside of the equatorial ionosphere penetrates through the dense $F$-layer by polarization electric field (Kelley, 1989). The bubbles, which are recognized as equatorial spread- $F$ on ionograms, have initially been detected by radio-sounding techniques (e.g. Booker and Wells, 1938; Woodman and La Hoz, 1976). Airglow imaging technique, on the other hand, is a powerful tool to detect spatial and temporal evolution of the bubble structures from ground and satellite (e.g. Mendillo and Baumgardner, 1982; Rohrbaugh et al., 1989; Tinsley et al., 1997; Aarons et al., 1999; Sahai et al., 2000; Makela and Kelley, 2003; Sagawa et al., 2003).

Recent development of highly-sensitive cooled-CCD camera raises sensitivity and quality of the airglow images. As-

Correspondence to: K. Shiokawa

(shiokawa@stelab.nagoya-u.ac.jp) sociated with this development, airglow imagers have been installed not only near the equator but also at midlatitudes, where the airglow intensity is relatively low. Mendillo et al. (1997) reported a bubble structure that reaches very high altitudes of more than $1500 \mathrm{~km}$ on the basis of midlatitude airglow-imaging observation at Arecibo, Puerto Rico $\left(18.3^{\circ} \mathrm{N}, 293.3^{\circ} \mathrm{E}\right.$; geomagnetic latitude: $29^{\circ} \mathrm{N}$, dip angle: $46^{\circ}$ ). Kelley et al. (2002) showed spectacular high-altitude plasma bubbles seen in the airglow images at Haleakala, Hawaii $\left(20.7^{\circ} \mathrm{N}, 203.8^{\circ} \mathrm{E}\right.$; geomagnetic latitude: $21^{\circ} \mathrm{N}$, dip angle: $37^{\circ}$ ). Otsuka et al. (2002) were the first to report clear geomagnetic conjugacy of the high-altitude plasma bubble on the basis of conjugate airglow imaging observations at Sata, Japan $\left(31.0^{\circ} \mathrm{N}, 130.7^{\circ} \mathrm{E}\right.$; geomagnetic latitude: $24^{\circ} \mathrm{N}$, dip angle: $\left.44^{\circ}\right)$ and Darwin, Australia $\left(12.4^{\circ} \mathrm{S}, 131.0^{\circ} \mathrm{E}\right.$; geomagnetic latitude: $22^{\circ} \mathrm{S}$, dip angle: $-40^{\circ}$ ). However, the bubbles reported by Otsuka et al. were a "fossil" of the bubbles, which were already formed near the sunset terminator and drifted into the field-of-view of the airglow imagers without changing their shape.

In this paper, we report time evolution of high-altitude plasma bubbles observed on 4 April 2002, at geomagnetic conjugate points at Sata and Darwin. Poleward growth and bifurcation of the bubbles were observed in the field-of-view of all-sky airglow imagers both in the evening (21:00 LT) and around midnight.

\section{Observation}

The all-sky airglow imagers used in this study were developed in the Solar-Terrestrial Environment Laboratory, Nagoya University, as part of the Optical Mesosphere Thermosphere Imagers (OMTIs) (Shiokawa et al. 1999, 2000). The imager at Sata, Japan, has been operating since July 2000. The imager at Darwin, Australia, has been operating since October 2001. The geomagnetic conjugate point of Darwin $\left(28.7^{\circ} \mathrm{N}, 131.4^{\circ} \mathrm{E}\right)$ is located $250 \mathrm{~km}$ southeast of Sata. Airglow images mapped from Darwin to the Northern 
COUNT
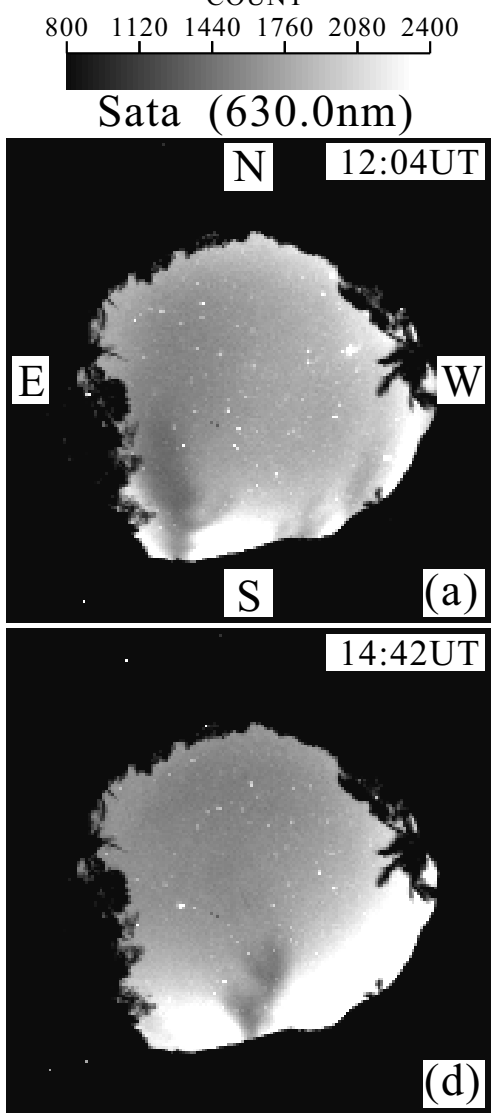

COUNT

200032004400560068008000

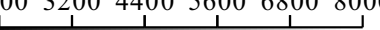

COUNT

160018802160244027203000

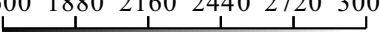

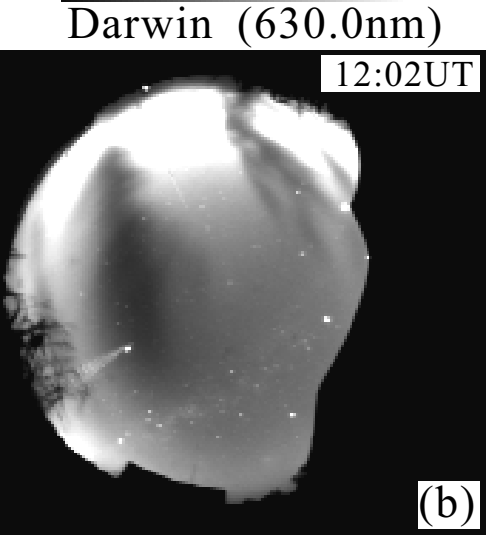

Darwin $(777.4 \mathrm{~nm})$
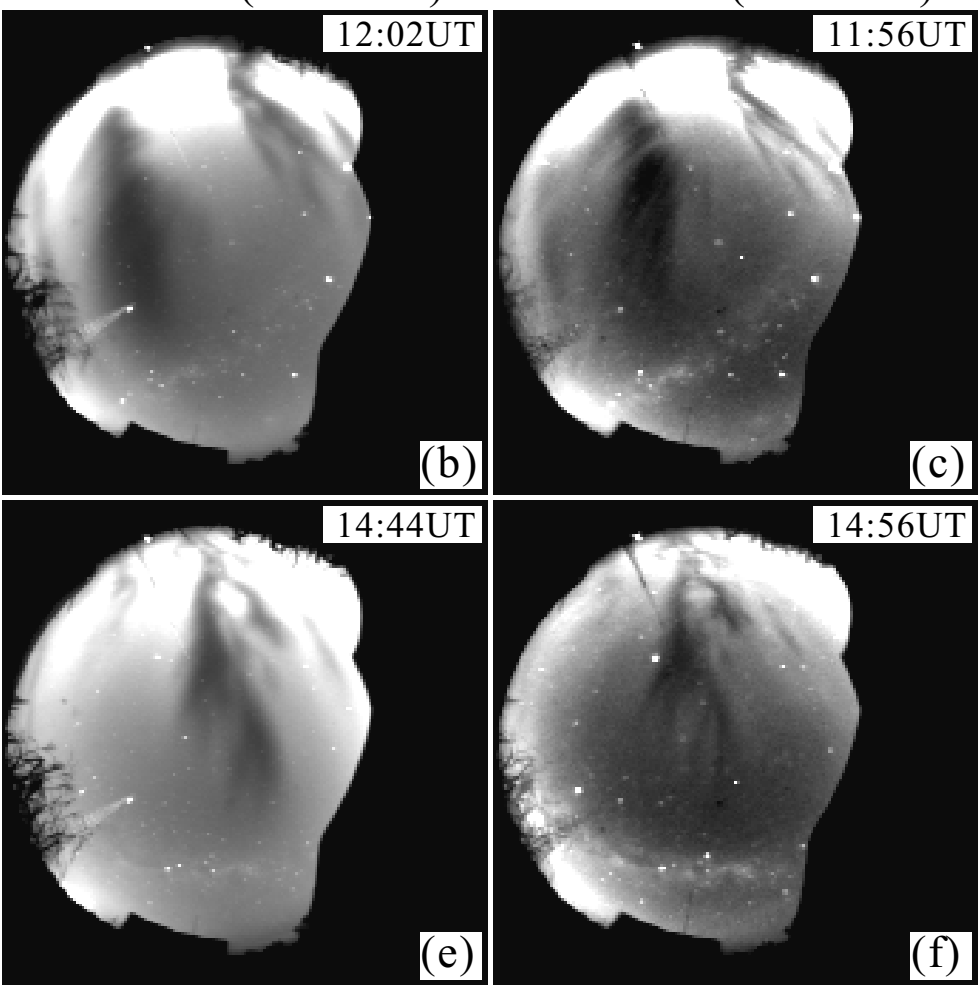

Fig. 1. All-sky airglow images at wavelengths of OI $630.0 \mathrm{~nm}$ and OI $777.4 \mathrm{~nm}$ observed at (a) and (d) Sata, Japan and (b), (c), (e), and (f) Darwin, Australia, on 4 April 2002. Local time of these stations is UT $+9 \mathrm{~h}$. The bubble structures (tree-like depletions of airglow intensity) are extended from south to north at Sata and from north to south at Darwin.

Hemisphere along the geomagnetic field line mostly overlap the airglow images at Sata, since the field-of-view of an all-sky imager is about $1000 \mathrm{~km}$ in diameter. Airglow images at a wavelength of $630.0 \mathrm{~nm}$ (OI, emission altitude: $200-300 \mathrm{~km}$ ) were obtained every $5.5 \mathrm{~min}$ and $6 \mathrm{~min}$ at Sata and Darwin, respectively, with an exposure time of $165 \mathrm{~s}$. Airglow images at $777.4 \mathrm{~nm}$ (OI, emission altitude: 300 $400 \mathrm{~km}$ ) were also obtained every $30 \mathrm{~min}$ at Darwin with the same exposure time. Background continuum emission from the sky were monitored every $30 \mathrm{~min}$ at a wavelength of $572.5 \mathrm{~nm}$, to estimate the absolute intensity of these airglow lines.

These airglow emissions are closely related to the $F$-region electron density (e.g. Tinsley et al., 1973; Sahai et al., 1981; Link and Cogger, 1988). The major chemical reactions that generate the $630.0-\mathrm{nm}$ airglow emission are:

$\mathrm{O}^{+}+\mathrm{O}_{2} \longrightarrow \mathrm{O}_{2}^{+}+\mathrm{O}$

$O_{2}^{+}+e^{-} \longrightarrow O\left({ }^{1} D\right)+O$

$O\left({ }^{1} D\right) \longrightarrow O\left({ }^{3} P\right)+h v_{630.0 n m}$
Because reaction Eq. (1) dominates the whole process, the production of the 630.0-nm emission is proportional to the molecular oxygen density $\left[\mathrm{O}_{2}\right]$ and the oxygen ion density $\left[\mathrm{O}^{+}\right]$. The oxygen ion density $\left[\mathrm{O}^{+}\right]$is nearly equal to the electron density $N_{e}$ in the $F$-layer. Thus, the 630.0 -nm emission is a sensitive indicator of the electron density in the bottomside of the $F$-layer.

The chemical reactions that generate the 777.4-nm airglow emission are:

$$
O^{+}+e^{-} \longrightarrow O\left({ }^{5} P\right)
$$

$$
O\left({ }^{5} \mathrm{P}\right) \longrightarrow O\left({ }^{5} S\right)+h v_{777.4 n m}
$$

Figure 2 shows the conjugate bubble images (in count rate) of Figs. 1a,b and converted onto a geographical map. The three bubble structures extend from the equator to both the Northern and Southern Hemispheres simultaneously. Note that the bubbles show latitudinal tilts (westward at higher latitudes), forming backward "C"-shapes on a global scale.

Figure 3 shows temporal evolution of a plasma bubble seen in the 630.0-nm images at Sata in the evening at 11:0412:17 UT (20:04-21:17 LT). All-sky images in Fig. 1 were 
converted into geographical images by assuming the peak airglow layer for $630.0-\mathrm{nm}$ emission of $250 \mathrm{~km}$. We focus on the bubble structure seen near the southwest edge of the raw all-sky images in Fig. 1a. Because of the steep gradient of airglow intensity from low to high latitudes, we show deviation images in units of $\%$ from 1-hour running averages, in order to see the shape of the plasma bubbles more clearly. The apex height of the magnetic field line at the equator is shown in the right of the panels, using the IGRF-2000 model.

The production of the 777.4-nm emission is proportional to both the oxygen ion density $\left[\mathrm{O}^{+}\right]$and the electron density $N_{e}$, and $\left[\mathrm{O}^{+}\right] \simeq N_{e}$ in the $F$-layer. Thus, the 777.4-nm intensity is proportional to the square of the electron density around the $F$-layer peak.

Figure 1 shows examples of plasma bubbles observed in the 630.0-nm and 777.4-nm airglow images at Sata and Darwin on 4 April 2002. The bubbles observed in the evening (21:00 LT) and at midnight (00:00 LT) are shown in the upper and lower panels, respectively. Local time (LT) is $9 \mathrm{~h}$ ahead of UT at these stations. The three images (Sata, $630.0 \mathrm{~nm}$; Darwin, $630.0 \mathrm{~nm}$ and $777.4 \mathrm{~nm}$ ) were nearly simultaneously taken. The bubbles, which can be identified as tree-like depletions of airglow intensity, are elongated from the south of Sata and from the north of Darwin. In the images of $777.4 \mathrm{~nm}$, the bubbles show ray-like fine-scale structures. Abalde et al. (2001) suggested that these ray-like structures indicate field-aligned irregularities developed in the bubble.

Fast evolution of a plasma bubble (indicated in blue as a depletion of airglow intensity) toward the higher latitude is seen in the images. The bubble appeared in the bottom of the image around $\left(27^{\circ} \mathrm{N}, 131^{\circ} \mathrm{E}\right)$ at 11:04 UT (20:04 LT) and developed to $\left(29^{\circ} \mathrm{N}, 132^{\circ} \mathrm{E}\right)$ at 11:34 UT (20:34 LT). The upward velocity of the bubble at the equator is estimated to be $170 \mathrm{~m} / \mathrm{s}$, by taking the apex height of the bubble at 11:04 UT and 11:34 UT to be $1100 \mathrm{~km}$ and $1400 \mathrm{~km}$, respectively. The airglow depletion in the bubble reaches to $-40 \%$ from 1-hour average airglow intensity. The bubble structure shows bifurcations to the right of the main structure from 11:17 UT to 11:34 UT and to the left from 11:47 UT to 12:04 UT (see also Fig. 5). The latter bifurcation produces a smaller branch, which has a width of $\sim 50 \mathrm{~km}$. This westernside bifurcation can be clearly identified in the raw image in Fig. 1a. The whole structure continuously moved eastward with a velocity of $\sim 100 \mathrm{~m} / \mathrm{s}$.

Figure 4 shows temporal evolution of a plasma bubble seen in the 630.0-nm images at Sata around midnight at 13:2815:28 UT (22:28-00:28 LT) in the same format as that in Fig. 3. The bubble can be identified as a blue torch-like structure in these panels. This bubble structure was seen in the south of the raw all-sky image in Fig. 1d. The bubble continuously moved eastward with a velocity of $\sim 80 \mathrm{~m} / \mathrm{s}$. It slowly evolves poleward, showing bifurcation around the top of the structure with a scale size of less than $50 \mathrm{~km}$. If we take the apex height of the bubble at 13:28 UT and 15:28 UT to be $1350 \mathrm{~km}$ and $1550 \mathrm{~km}$, respectively, the upward velocity of the bubble at the equator is estimated to be $28 \mathrm{~m} / \mathrm{s}$.

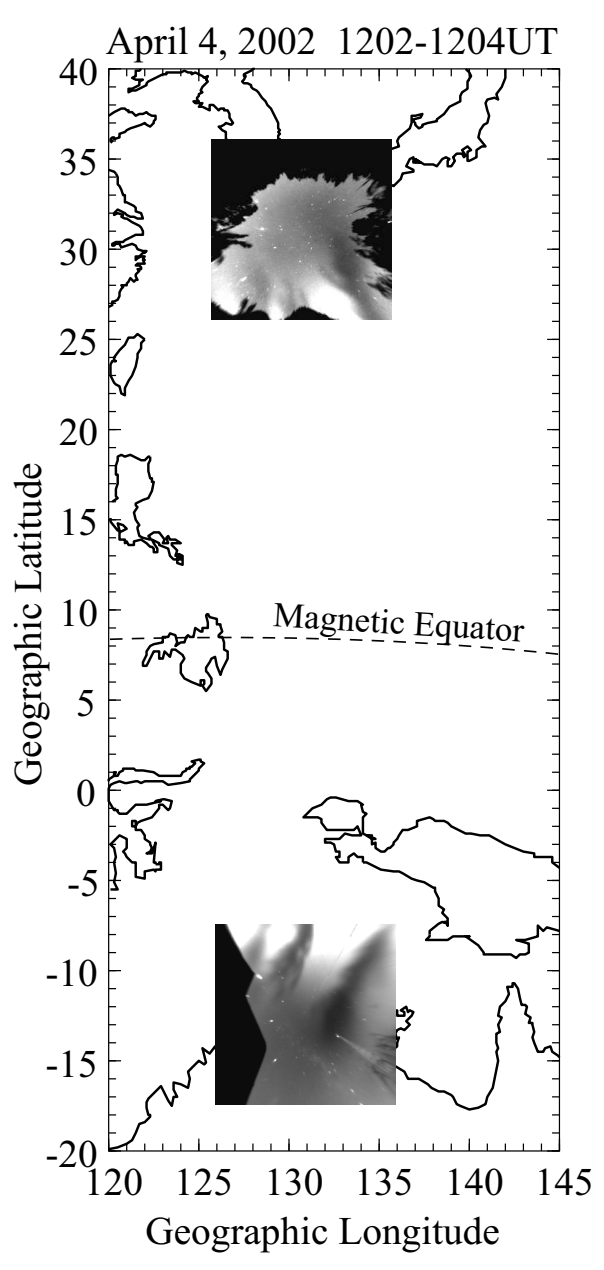

Fig. 2. Plasma bubble images (in count rate) at Sata and Darwin on a geographical map. These images were obtained at 12:04 UT (Sata) and 12:02 UT (Darwin) on 4 April 2002. Note that the bubbles show latitudinal tilts, forming backward "C"-shapes.

To see geomagnetic conjugacy of these bubbles, we show 630.0-nm airglow images nearly simultaneously obtained at Sata and Darwin in Fig. 5, in the same format as those in Figs. 3 and 4. The all-sky images at Darwin were converted to geographical coordinates in the Northern Hemisphere (same to those at Sata), using the IGRF-2000 geomagnetic field model (Mandea and Macmillan, 2000). The white curves in the top three panels indicate envelopes of the bubble structures at Sata. The same curves are indicated in the images of Darwin in the bottom three panels for comparison. For both the evening and midnight events, the correspondence of the bubble structures between the Northern and Southern Hemispheres is fairly good, even for the small bifurcated structures with a scale size of less than $\sim 50 \mathrm{~km}$.

\section{Discussion}

We observed growth and bifurcation of high-altitude plasma bubbles at geomagnetic conjugate stations at midlatitudes. The correspondence of the bubble growth between the two 


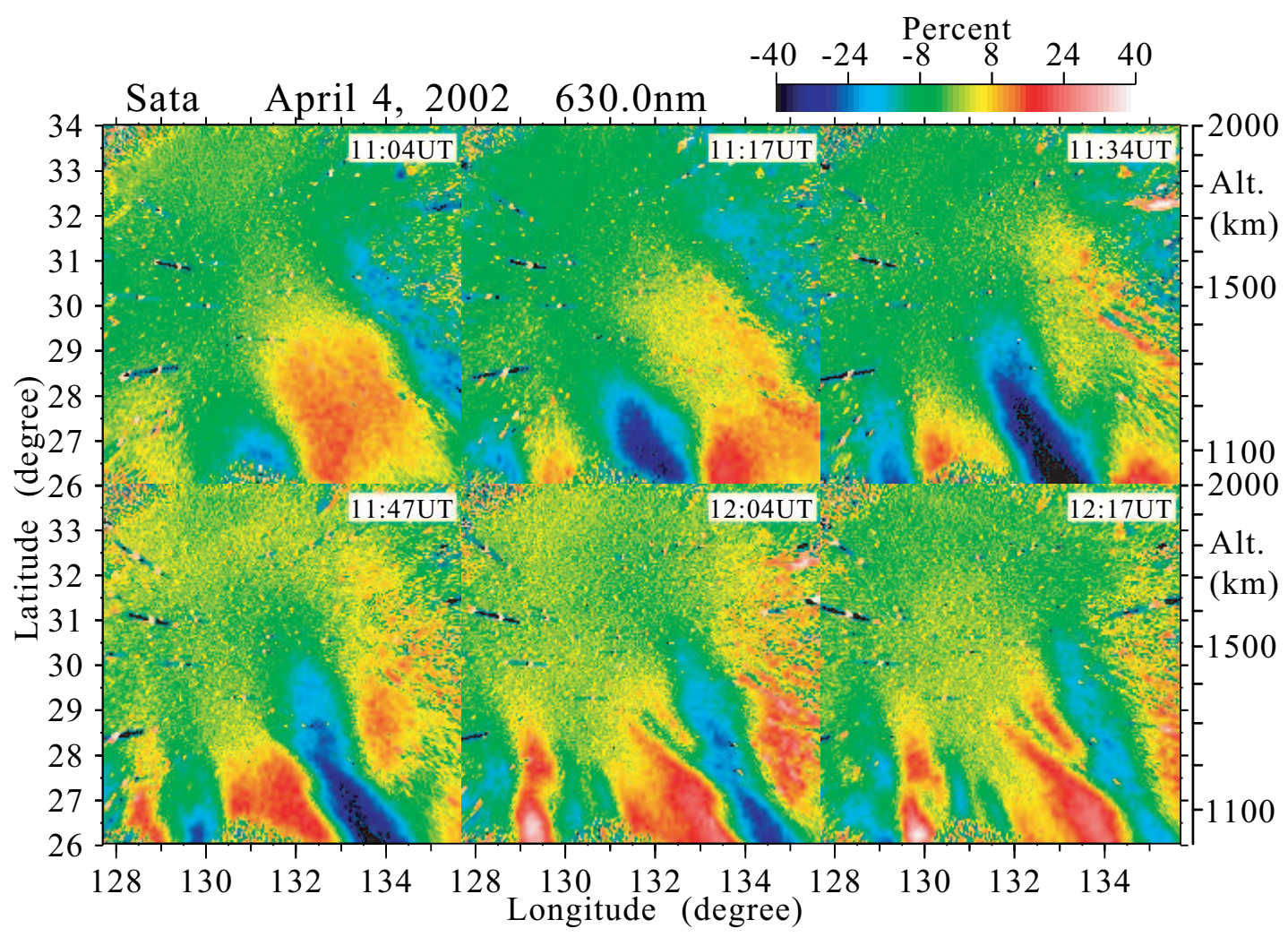

Fig. 3. Evolution of the plasma bubble structure seen in the 630.0-nm airglow images at Sata, Japan, at 11:04-12:17 UT (20:04-21:17 LT) on 4 April 2002. The raw all-sky images were converted into geographic coordinates by assuming an airglow height of $250 \mathrm{~km}$. The images are deviations in unit of $\%$ from 1-hour running averages. The apex height of the magnetic field line at the equator is shown in the right of the panels. The bubble structure can be identified in blue (depletion of airglow intensity) extending from lower to higher latitudes.

hemispheres is fairly good even for the small-scale structures of less than $50 \mathrm{~km}$. This result indicates that the evolution and bifurcation of plasma bubble occur on the entire field line simultaneously with a horizontal north-south scale size of $\sim 5000 \mathrm{~km}$, as indicated in Fig. 2.

It should be noted that the bubbles are not often observed at these midlatitude stations. The occurrence of the bubble in the Japanese longitudinal sector peaks around the equinox seasons and during the solar maximum period (Maruyama and Matuura, 1984; Tsunoda, 1985; Sahai et al., 2000), consistent with the prereversal enhancement maximum of the background eastward electric field observed at Jicamarca in Peru (Fejer et al., 1991). The event reported here took place during the solar maximum period in the equinox.

The upward velocities of the bubble growth were $170 \mathrm{~m} / \mathrm{s}$ at 21:00 LT and $28 \mathrm{~m} / \mathrm{s}$ at 00:00 LT. The value of $170 \mathrm{~m} / \mathrm{s}$ is consistent to that in the previous literature (e.g. $125-350 \mathrm{~m} / \mathrm{s}$ by Tsunoda et al., 1981). However, the latter value of $28 \mathrm{~m} / \mathrm{s}$ at 00:00 LT is much slower than the velocity at 21:00 LT. This fact may indicate dependence of bubble growth speed on bubble age. The bubble-top latitudes in the Sata images start from $\sim 27^{\circ} \mathrm{N}$ in Fig. 3 and $\sim 29^{\circ} \mathrm{N}$ in Fig. 4. Thus, the latter bubble at 00:00 LT might be created earlier and drifted into the Sata field-of-view. The latter (old) bubble might have a smaller upward drift velocity.
The observed bubbles in Figs. 2-5 tilt from west (high altitudes) to east (low altitudes). A similar tilt of the bubble has initially been reported by Woodman and $\mathrm{La} \mathrm{Hoz}$ (1976), Tsunoda et al. (1981) and Mendillo and Tyler (1983) and more recently by airglow imaging from the ground (e.g. Makela and Kelley, 2003) and from satellites (Kelley et al., 2003; Kil et al., 2004). Woodman and La Hoz (1976) initially explained this tilt by height-dependent reduction of eastward drift velocities of the bubbles due to the polarization electric field inside the bubbles. Zalesak et al. (1982) made further theoretical considerations and concluded that this tilt indicates velocity shear of the $F$-region plasma due to the incomplete coupling of the plasma motion to the eastward neutral wind, depending on the Pedersen conductivities both in the $F$-region (lower latitudes) and $E$-region (higher latitudes). On the other hand, Anderson and Mendillo (1983) explained this westward tilt by the possible latitudinal decrease of zonal wind velocity with increasing latitudes.

The temporal decrease of the eastward drift velocity was detected from the eastward motion of the bubbles $(\sim 100 \mathrm{~m} / \mathrm{s}$ and $\sim 80 \mathrm{~m} / \mathrm{s}$ at 21:00 and 00:00 LT, respectively). Neutral wind in the thermosphere was observed on this night through a Doppler shift of 630.0-nm airglow using a FabryPerot interferometer at Shigaraki, Japan $\left(34.8^{\circ} \mathrm{N}, 136.1^{\circ} \mathrm{E}\right.$, about $660 \mathrm{~km}$ northeast of Sata) (Shiokawa et al., 2003). The 


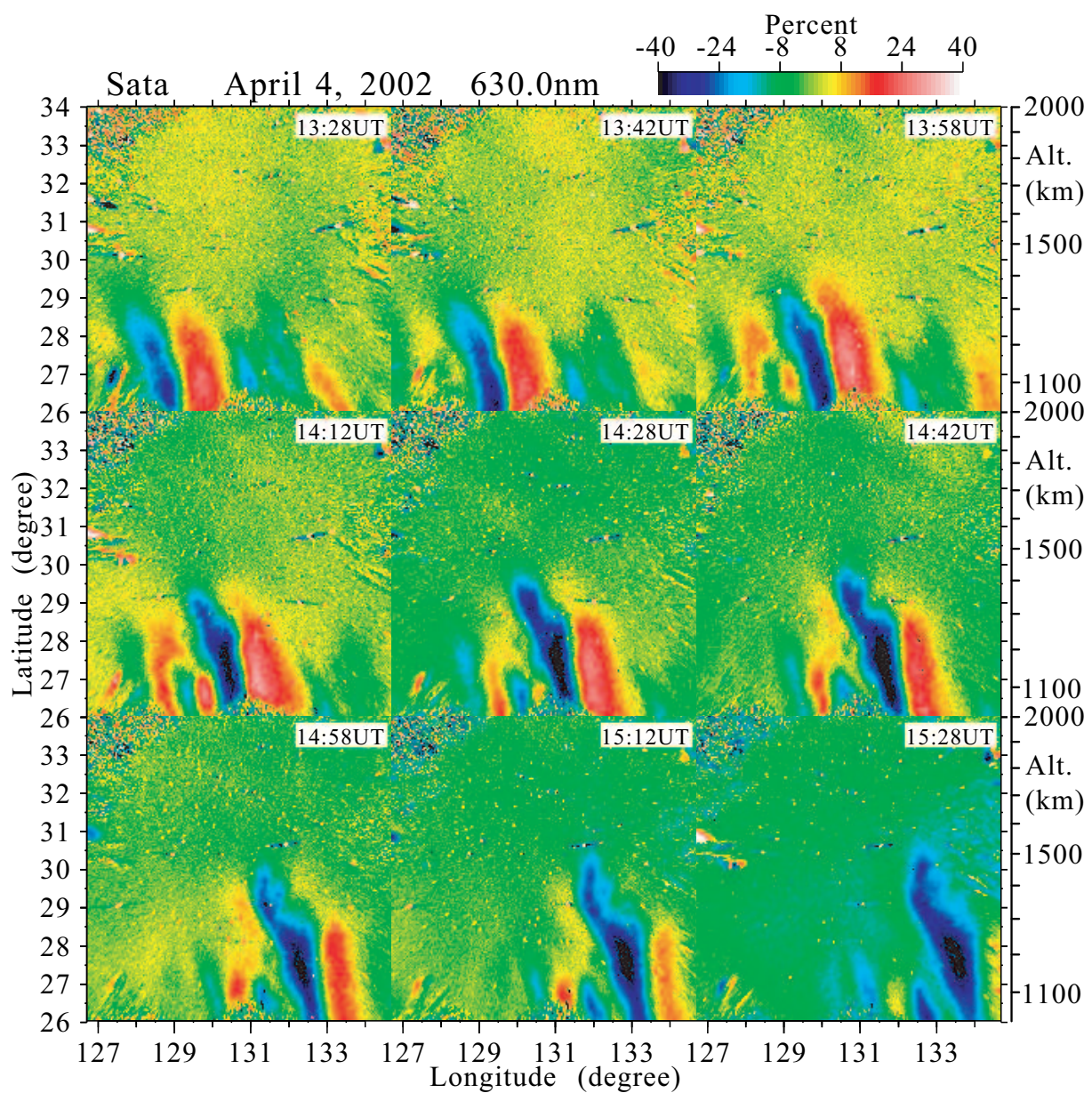

Fig. 4. Evolution of the plasma bubble structure seen in the 630.0-nm airglow images at Sata, Japan, at 13:28-15:28 UT (22:28-00:28 LT) on 4 April 2002, in the same format as that in Fig. 3.

eastward neutral wind velocity on this night decreases from $\sim 120 \mathrm{~m} / \mathrm{s}$ at 21:00 LT to $\sim 50 \mathrm{~m} / \mathrm{s}$ at 00:00 LT. The observed decrease of the eastward drift velocity of the bubbles probably corresponds to the observed decrease of background neutral wind in the thermosphere.

The high-altitude plasma bubbles reported in this paper were observed in the evening (around 21:00 LT) and at midnight (00:00 LT). It is somewhat unusual to observe the bubble growth around midnight, since equatorial plasma bubbles develop around the evening terminator where the vertical drift of the $F$-layer is often strongly upward (Fejer et al., 1991). Fejer et al. (1999) concluded that the generation of late-night spread- $F$ requires the reversal of the vertical velocity from downward to upward for periods longer than about half an hour.

In order to see nocturnal variation of the ionosphere, we plotted 630.0-nm airglow intensities observed at Sata and Darwin in Fig. 6. The airglow intensities at $\left(27.0^{\circ} \mathrm{N}\right.$, $\left.131.0^{\circ} \mathrm{E}\right)$ and $\left(30.0^{\circ} \mathrm{N}, 131.0^{\circ} \mathrm{E}\right)$ are extracted from the airglow images. The plasma bubble passages can be identified as temporal depletions of the intensities, particularly at $27^{\circ} \mathrm{N}$. The intensity decreases from 19:00 LT to 20:30 LT due to the decrease of $F$-layer electron density after sunset. However, it turns to an increase from 20:30-21:00 LT at both Sata and Darwin, and further increases drastically after 23:30-00:00 LT at Sata. These enhancements of 630.0$\mathrm{nm}$ airglow intensity may suggest upward drift of the equatorial $F$ layer and subsequent supply of electrons to midlatitudes along the field line, which is consistent with the suggestion by Fejer et al. (1999) on the generation of late-night plasma bubbles. Although a magnetic substorm occurs at 20:00-23:00 LT, the $K_{p}$ index was very small (2- and 2, $\left.\Sigma K_{p}=11\right)$ on this night. The ionogram data obtained at Yamagawa ( $\sim 20 \mathrm{~km}$ north of Sata) do not show upward motion of the nighttime $F$-layer. Thus, global penetration of magnetospheric electric field and disturbance dynamo seem not to be the cause of the possible $F$-layer rise on this night. Other dynamic variation of the neutral atmosphere at the equator may contribute to the layer rise and the airglow intensity enhancement. The drastic enhancement after 23:30 LT at Sata may correspond to a large-scale atmospheric wave propagating from the midnight temperature maximum in the equator (e.g. Colerico et al., 1996; Otsuka et al., 2003). 


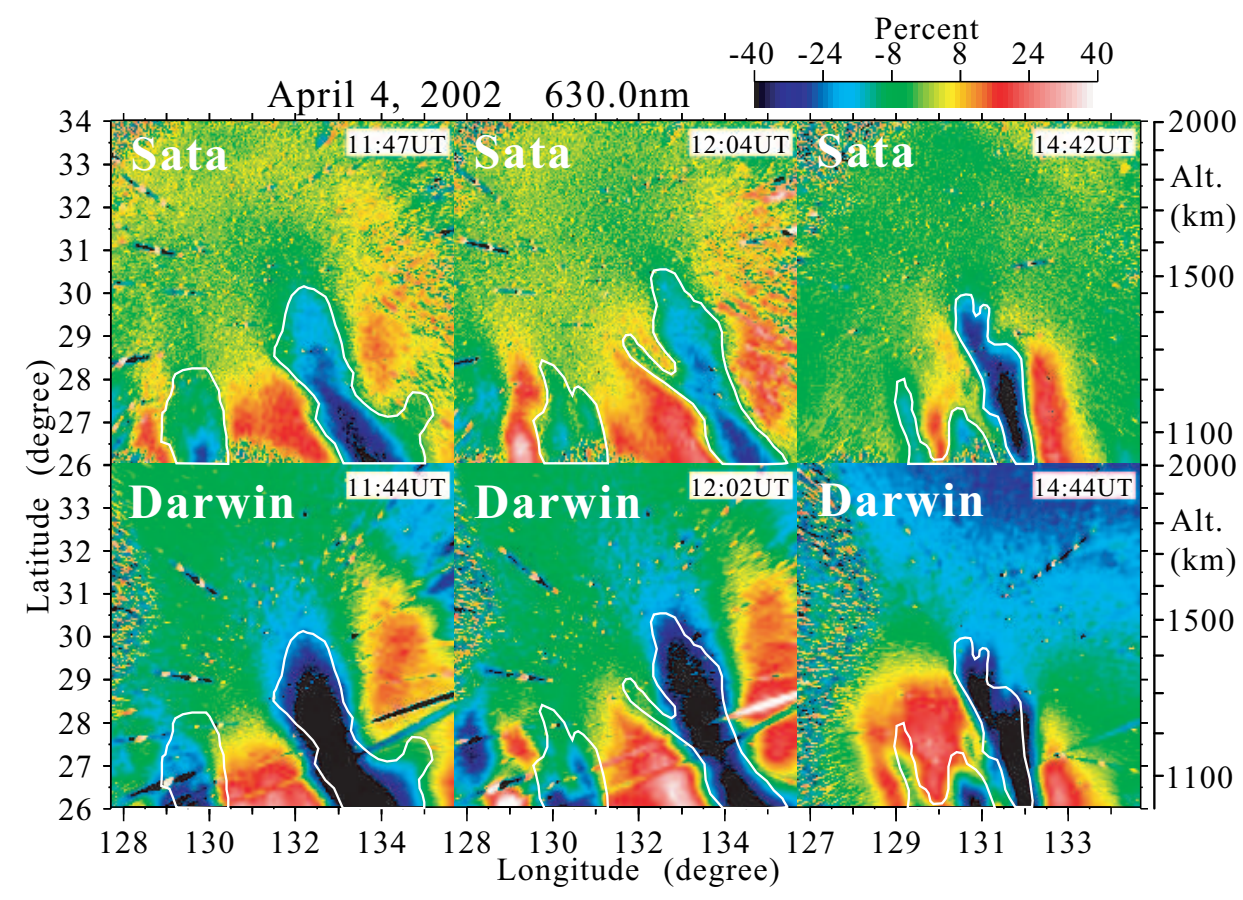

Fig. 5. Comparison of the plasma bubble structures observed in the 630.0-nm airglow images at Sata, Japan, and Darwin, Australia, on 4 April 2002, in the same format as that in Figs. 3 and 4. The airglow images at Darwin (bottom three panels) are those converted to the Northern Hemisphere using the IGRF magnetic field model. The white curves in the top three panels show envelopes of the bubble structures at Sata. The same curves are indicated in the bottom three panels to compare the bubble structures between Sata and Darwin. The two lines seen at the bottom right of the Darwin images at 11:44 UT and 12:02 UT are airplane trajectories.

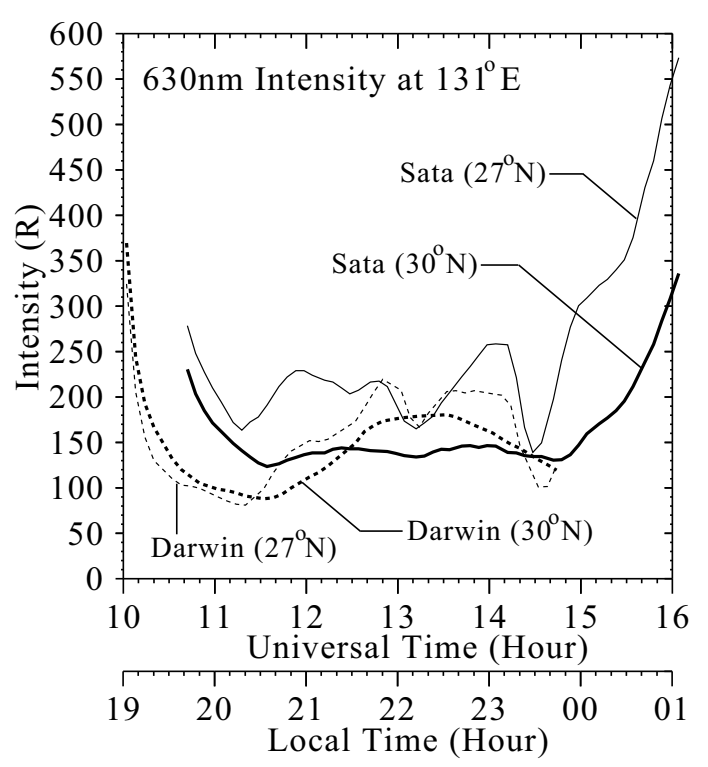

Fig. 6. Variation of nocturnal 630.0-nm airglow intensities at Sata and Darwin on 4 April 2002. The intensities were extracted from airglow images at Sata and Darwin at geographic locations of $\left(27.0^{\circ} \mathrm{N}, 131.0^{\circ} \mathrm{E}\right)$ and $\left(30.0^{\circ} \mathrm{N}, 131.0^{\circ} \mathrm{E}\right)$ in the Northern Hemisphere (Darwin images were converted to the Northern Hemisphere, as shown in Fig. 5).

\section{Conclusion}

We reported temporal evolution and bifurcation features of equatorial plasma bubbles, on the basis of airglow imaging observations at midlatitude geomagnetic-conjugate stations (magnetic latitudes: $22-24^{\circ}$ ) on 4 April 2002. The bubbles reach apex heights of $\sim 1500 \mathrm{~km}$ at the equator. The correspondence of the bubble growth between the two hemispheres is fairly good, even for the small-scale structures of less than $50 \mathrm{~km}$, indicating that the bubble growth and bifurcation occur for the entire field line simultaneously with a north-south scale size of $\sim 5000 \mathrm{~km}$. The observed properties of poleward (upward) and eastward velocities and the tilt of the bubbles are consistent to the observations and theories reported in previous literature.

Acknowledgements. We thank Y. Katoh, M. Satoh, T. Katoh, and K. Hidaka of the Solar-Terrestrial Environment Laboratory, Nagoya University, for their kind support of the development and operation of the all-sky imagers. The all-sky imager at Darwin was operated at the ionosonde station of the IPS Radio and Space Services, Australia. This work was supported by Grant-in-Aid for Scientific Research (11440145 and 13573006) and on Priority Area (764) of the Ministry of Education, Culture, Sports, Science and Technology of Japan .

Topical Editor M. Lester thanks H. Kil and another referee for their help in evaluating this paper. 


\section{References}

Aarons, J., Mendillo, M., Lin, B., Colerico, M., Beach, T., Kintner, P., Scali, J., Reinisch, B., Sales, G., and Kudeki, E.: Equatorial $F$-region irregularity morphology during an equinoctial month at solar minimum, Space Sci. Rev., 87, 357-386, 1999.

Abalde, J. R., Fagundes, P. R., Bittencourt, J. A., and Sahai Y.: Observations of equatorial $F$-region plasma bubbles using simultaneous OI $777.4 \mathrm{~nm}$ and OI $630.0 \mathrm{~nm}$ imaging: New results, J. Geophys. Res., 106, 30 331-30 336, 2001.

Anderson, D. N. and Mendillo, M.: Ionospheric conditions affecting the evolution of equatorial plasma depletions, Geophys. Res. Lett., 10, 541-544, 1983.

Booker, H. G. and Wells, H. W.: Scattering of radio waves by the $F$ region of the ionosphere, J. Geophys. Res., 43, 249-256, 1938.

Colerico, M., Mendillo, M., Nottingham, D., Baumgardner, J., Meriwether, J., Mirick, J., Reinisch, B. W., Scali, J. L., Fesen, C. G., and Biondi, M. A.: Coordinated measurements of $F$ region dynamics related to the thermospheric midnight temperature maximum, J. Geophys. Res., 101, 26 783-26 793, 1996.

Fejer, B. G., de Paula, E. R., González, S. A., and Woodman, R. F.: Average vertical and zonal $\mathrm{F}$ region plasma drifts over Jicamarca, J. Geophys. Res., 96, 13 901-13 906, 1991.

Fejer, G., Scherliess, L., and de Paula, E. R.: Effects of the vertical plasma drift velocity on the generation and evolution of equatorial spread F, J. Geophys. Res., 104, 19859-19 869, 1999.

Kelley, M. C.: The Earth's ionosphere, Plasma Physics and Electrodynamics, Academic Press, San Diego, California, 1989.

Kelley, M. C., Makela, J. J., Ledvina, B. M., and Kintner, P. M.: Observations of equatorial spread-F from Haleakala, Hawaii, Geophys. Res. Lett., 29, doi:10.1029/2002GL015509, 2002.

Kelley, M. C., Makela, J. J., Paxton, L. J., Kamalabadi, F., Comberiate, J. M., and Kil, H.: The first coordinated ground- and spacebased optical observations of equatorial plasma bubbles, Geophys. Res. Lett., 30, 1766, doi:10.1029/2003GL017301, 2003.

Kil, H., Su, S.-Y., Paxton, L. J., Wolven, Y., Zhang, B. C., Morrison, D., and Yeh,H. C.: Coincident equatorial bubble detection by TIMED/GUVI and ROCSAT-1, Geophys. Res. Lett., 31, L03809, doi:10.1029/2003GL018696, 2004.

Link, R. and L. L. Cogger: A reexamination of the O I 6300-A nightglow, J. Geophys. Res., 93, 9883-9892, 1988 (correction on J. Geophys. Res., 94, 1556, 1989).

Makela, J. J. and Kelley, M. C.: Field-aligned 777.4-nm composite airglow images of equatorial plasma depletions, Geophys. Res. Lett., 30(8), 1442, doi:10.1029/2003GL017106, 2003.

Maruyama, T. and Matsuura, N.: Longitudinal variability of annual changes in activity of equatorial spread $F$ and plasma bubbles, J. Geophys. Res., 89, 10903-10 912, 1984.

Mandea, M. and Macmillan, S.: International geomagnetic reference field - the eighth generation, Earth Planets Space, 52, 11191124, 2000.

Mendillo, M. and Baumgardner, J.: Airglow characteristics of equatorial plasma depletions, J. Geophys. Res., 87, 7641-7652, 1982.

Mendillo, M. and Tyler, A.: Geometry of depleted plasma regions in the equatorial ionosphere, J. Geophys. Res., 88, 5778-5782, 1983.

Mendillo, M., Baumgardner, J., Nottingham, D., Aarons, J., Reinisch, B., Scali, J., and Kelley, M. C.: Investigations of thermospheric-ionospheric dynamics with $6300 \mathrm{~A}$ images from the Arecibo Observatory, J. Geophys. Res., 102, 7331-7343, 1997.
Otsuka, Y., Shiokawa, K., Ogawa, T., and Wilkinson, P.: Geomagnetic conjugate observations of equatorial airglow depletions, Geophys. Res. Lett., 29, No.15, doi:10.1029/2002GL015347, 2002.

Otsuka, Y., Kadota, T., Shiokawa, K., Ogawa, T., Kawamura, S., Fukao, S., and Zhang, S.-R.: Optical and radio measurements of a 630-nm airglow enhancement propagating over Japan on 9 September, 1999, J. Geophys. Res., 108(A6), 1252, doi:10.1029/2002JA009594, 2003.

Rohrbaugh, R. P., Hanson, W. B., Tinsley, B. A., Cragin, B. L., McClure,J. P., and Broadfoot, A. L.: Images of transequatorial bubbles based on field-aligned airglow observations from Haleakala in 1984-1986, J. Geophys. Res., 94, 6763-6770, 1989.

Sagawa, E., Maruyama, T., Immel, T. J., Frey, H. U., and Mende, S. B.: Global view of the nighttime low-latitude ionosphere by the IMAGE/FUV $135.6 \mathrm{~nm}$ observations, Geophys. Res. Lett., 30, doi:10.1029/2003GL017140, 2003.

Sahai, Y., Bittencourt, J. A., Teixeira, N. R., and Takahashi, H.: Simultaneous observations of OI 7774-A and OI 6300-A emissions and correlative study with ionospheric parameters, J. Geophys. Res., 86, 3657-3660, 1981.

Sahai, Y., Fagundes, P. R., and Bittencourt, J. A.: Transequatorial F-region ionospheric plasma bubbles: solar cycle effects, J. Atmos. Solar-Terr. Phys., 62, 1377-1383, 2000.

Shiokawa, K., Katoh, Y., Satoh, M., Ejiri, M. K., Ogawa, T., Nakamura, T., Tsuda, T., Wiens, R. H.: Development of optical mesosphere thermosphere imagers (OMTI), Earth Planets Space, 51, 887-896, 1999.

Shiokawa, K., Katoh, Y., Satoh, M., Ejiri, M. K., and Ogawa, T.: Integrating-sphere calibration of all-sky cameras for nightglow measurements, Adv. Space Sci., 26, 1025-1028, 2000.

Shiokawa, K., Kadota, T., Otsuka, Y., Ogawa, T., Nakamura, T., and Fukao, S.: A two-channel Fabry-Perot interferometer with thermoelectric-cooled CCD detectors for neutral wind measurement in the upper atmosphere, Earth Planets Space, 55, 271-275, 2003.

Tinsley, B. A., Christensen, A. B., Bittencourt, J., Gouveia, H., Angreji, P. D., and Takahashi, H.: Excitation of oxygen permitted line emissions in the tropical nightglow, J. Geophys. Res., 78, 1174-1186, 1973.

Tinsley, B. A., Rohrbaugh, R. P., Hanson, W. B., and Broadfoot, A. L.: Images of transequatorial $F$ region bubbles in 630- and 777$\mathrm{nm}$ emissions compared with satellite measurements, J. Geophys. Res., 102, 2057-2077, 1997.

Tsunoda, R. T.: Control of the seasonal and longitudinal occurrence of equatorial scintillations by the longitudinal gradient in integrated $E$ region Pedersen conductivity, J. Geophys. Res., 90, 447-456, 1985.

Tsunoda, R. T., Livingston, R. C., and Rino, C. L.: Evidence of a velocity shear in bulk plasma motion associated with the postsunset rise of the equatorial F-layer, Geophys. Res. Lett., 8, 807810, 1981.

Woodman, R. F. and La Hoz, C.: Radar observations of $F$ region equatorial irregularities, J. Geophys. Res., 81, 5447-5466, 1976.

Zalesak, S. T., Ossakow, S. L., and Chaturvedi, P. K.: Nonlinear equatorial spread $F$ : The effect of neutral winds and background Pedersen conductivity, J. Geophys. Res., 87, 151-166, 1982. 